\title{
Automatic Measurement of Material Weight Based on Energy Load in Assembly Line Drives
}

\author{
Ivana Klačková ${ }^{*}$, Ivan Zajačko $^{1}$, and Miroslav Císar $^{1}$ \\ ${ }^{1}$ University of Žilina, The Faculty of Mechanical Engineering, Department of Automation and \\ Production Systems, Univerzitná 8215/1, 01026 Žilina, Slovakia
}

\begin{abstract}
The management of the universal self-stacker in the assembly line handles many different operations, which differ in the complexity of the solved problems, the response time of the controller, energy and other parameters. It is usually used one controller with all the features that have a lot of external input-output modules and have to deal with many tasks in parallel. The management application must be very complicated and blind with the risk of collision management processes and the need to address the priority of the management process. If the processes are divided into groups, each group of processes is solved by a separate controller. For simple processes, where appropriate, can be used for immediate response simple and easy to control, it is necessary to solve complex management processes using a controller with sufficient power, energy load, math performance and sufficient memory.
\end{abstract}

\section{Introduction}

The Universal shelf-stacker (USS), is equipment that stores shelves on the assembly line, so that residual space is minimized and the storage space in universal shelf-stacker is very energy and efficiently used (Figure 1). This equipment is contained in 2 towers, between them there is vertically movable equipment, that manipulates the shelves - extractor. The extractor inserts the shelf into the tower assembly line in another position. The hood can only be handled with one shelf at a time. The shelves can be placed in the tower in another position to avoid collision with other shelves or shelves or with another object of mechanical construction of universal shelf-stacker. There is dispensing opening, in tower the maximum height of the assembly line shelf, in which operating personal can handle with shelf content or a shelf. When shelf is putting into the universal shelf-stacker from dispensing slot, the maximum high of assembly line shelf is measured [1]. This item is very important to create space for the shelf. When moving the shelf from the suction space to the extractor, the weight of the shelf contents is measured by a special method - energy load. When the weight limit is exceeded, the USS does not insert the shelf into the tower, but returns it to the dispensing opening.

\footnotetext{
*Corresponding author: ivana.klackova@,fstroj.uniza.sk
} 
The movement of the moving parts of the universal shelf-stacker is performed by actuators - a three-phase asynchronous motor, only one of which is connected to the output of the converter. This solution for assembly lines sufficient for movement, because it follows from the principle of the universal shelf-stacker that it is not possible to move in the vertical and horizontal directions at the same time.

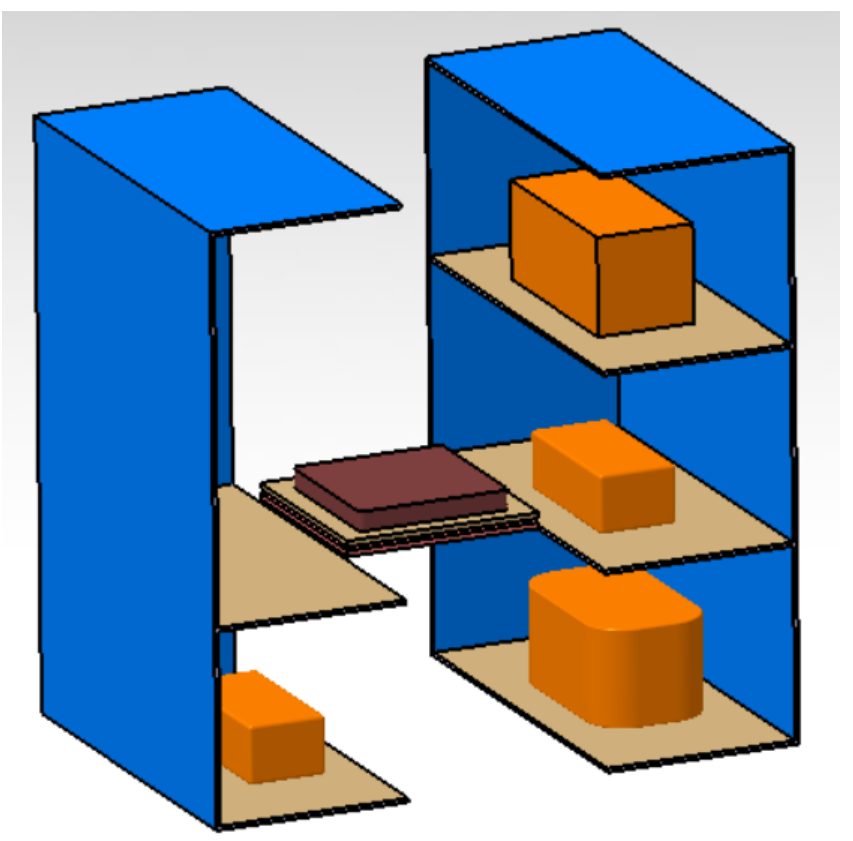

Fig. 1. Scheme of universal shelf-stacker. blue - towers of universal shelf-stacker, blue - dispensing slot, brown - shelves, dark brown - extractor, orange - items on the shelves.

\section{Aims and methodology}

The control system of universal shelf-stacker is complicated set of electronic components, sensors, actuators, safety elements and so on [11]. Control system must perform:

- $\quad$ synchronous performing more tasks with various priority of processing,

- $\quad$ synchronous performing more tasks with various time of reaction,

- performing input data from sensors, measuring components, back-coupling components, etc.,

- controlling many types of actuators,

- communication with outer system,

- $\quad$ communication interface for operating personal and servicemen [11].

The process of controlling a universal shelf stacker has to handle many different processes, which differ in their complexity and time response. As a rule, the process, which requires a shorter reaction time, is simpler. The simplest processes need the shortest reaction time (eg. emergency stop) and the processes we have to control based on a complex algorithm usually do not need an immediate response (eg. to create the best position to place the shelf in the universal shelf stacker).

The control system for light processes usually requires different hardware than the control system for a complex process, therefore the control system of the universal rack stacker is divided into 4 layers with a vertical hierarchy. These layers are interconnected by communication channels (see Figure 2). Each of the control layers may be implemented on 
a different hardware platform, but this does not preclude the connection of any layers with the same hardware platform on one unit.

With hardware design, layers can be created on other hardware platforms:

8-bit microprocessor (e.g. from Intel, Atmel, PIC, Fairchild, Motorola and others)

32-bit microprocessor from Atmel, ARM, Intel, Motorola or other companies

Many types of PLC (programmable logic controller) from many companies (B\&R,

Siemens, Unitronics, Panasonic, Rockwell Automation, ...)

Industrial PC for harsh industrial environments.

The universal shelf-stacker control layers are divided according to the response and operation time into 4 independent parts, which are in a vertical hierarchical structure.

\subsection{Zero layer control system of the universal stacker}

Collect data from position sensors, end position sensors, extractor shelf presence and dosing slot sensors, synchronized and safety sensors. The layer zero also works with the actuators in such a way that, through its outputs, it controls the connecting elements enabling the movement and switching of energy from the frequency converter between the motors of the moving parts. This layer is the fastest and its reaction time is the shortest in the process of inspecting the moving parts of the universal stacker. Together, the processes that control the zero layer are very simple and easy. Thus, a simple programmable component is sufficient for a layer zero control system that can prepare data from multiple digital inputs and can control multiple digital outputs [7].

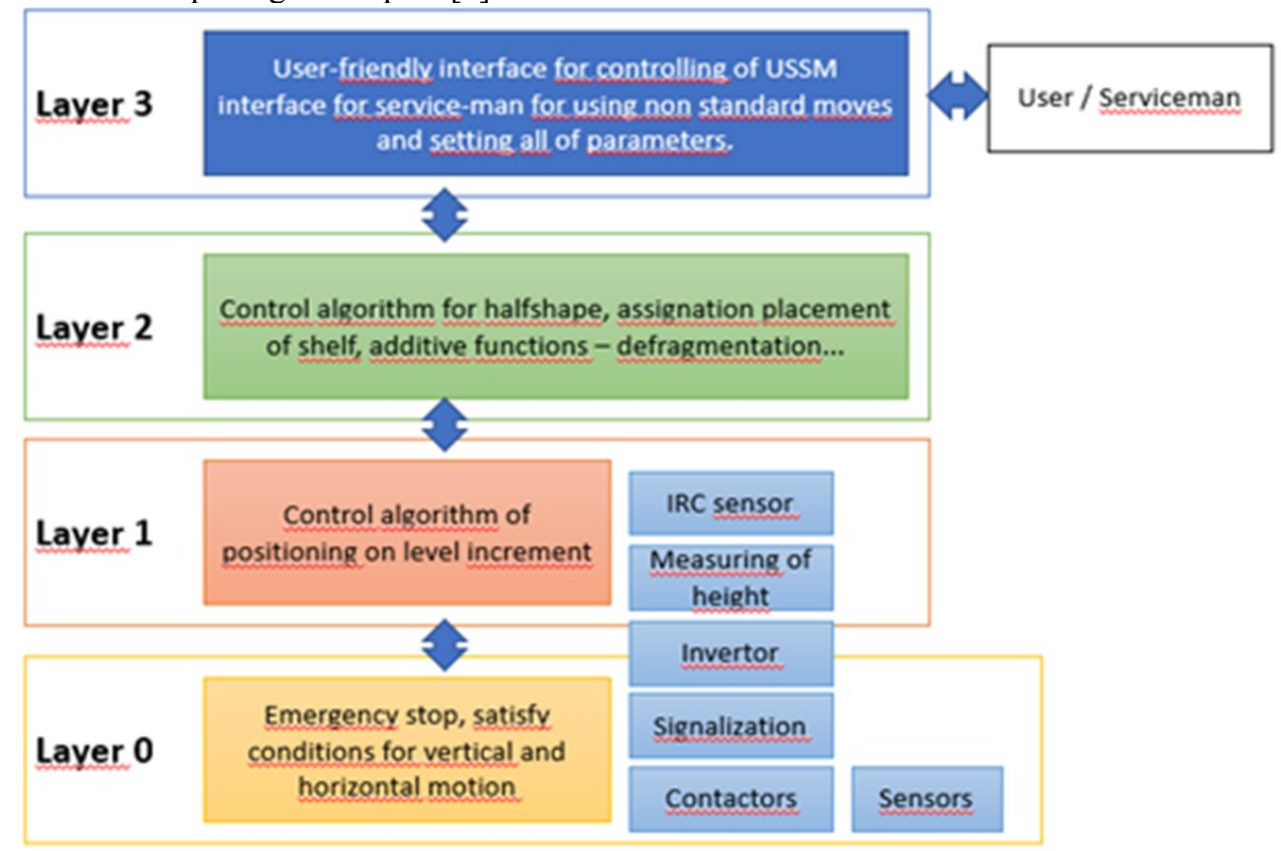

Fig. 2. Hierarchical layer structure of the universal shelf-stacker module control system.

\subsection{The second layer of the universal shelf-stacker control system}

Contains universal shelf-stackers of electrode control algorithms. It determines whether the task is feasible, which means that the algorithm defines that the shelf can be inserted into the UCS based on the measured shelf height, the measured shelf weight and the distribution 
of the positions of the other shelves on the universal shelf stacker. In the next step, layer two decides on the ideal position of the shelf for economical use of storage space. The second layer addresses all optional functions of the universal stacker such as defragmenting storage space, loading new racks for use in the universal stacker and unloading racks, temporarily decommissioning and returning racks, restoring the universal stacker after an electrical disaster, after an emergency stop, etc. The operating and system data are stored on the second layer and all parameters of the universal rack stacker are stored on this layer (description of the position of the free zones, mechanical parts of the universal rack stacker, parameter packages for the frequency converter). The second layer stores operational data as a data package for operating the universal rack stacker, rack database, data backup, which are used on the recovery machine after a non-standard interruption of operation $[2,8]$.

\subsection{Layer three of universal shelf-stacker control system}

Is a graphical, user-friendly interface designed for users of the universal shelf-stacker and service personnel (HMI - Human Machine Interface). Layer three makes it possible to manage the universal shelf-stacker by means of a menu very easily and users can use all the functions of the universal shelf-stacker which are intended for users at the level, e.g. get a shelf from the universal shelf-stacker. The administrator can use the HMI to read statistics on the operation of the universal shelf-stacker, the frequency of use of the shelves, manage users and their user rights to racks (which the rack user can obtain from the universal shelfstacker), can load and delete shelves to or from the device and can temporarily load and unload shelves from use. Through the HMI, service personnel can completely set all the parameters of the universal rack stacker in a user-friendly interface, they can define the mechanical view of the machine, the places where the mechanical reinforcements of the machine are located, the dispensing opening. They can define the positions of free zones in which shelves are located. Service personnel can check the functions of all sensors of all types that are located in the universal shelf-stacker. Servants can move independently of the actuators using the controls in situations where the movement is not safe or they are in conflict with the basic logic of the moving parts of the universal shelf-stacker.

\section{Results}

The universal shelf-stacker control unit is manufactured on an 8-bit microprocessor base from Atmel (layers zero and layer one) and on a platform industrial PC (layers two and layer three). Layer zero is implemented on an AtMega 128 microprocessor that has sufficient memory space for the software and has a sufficient number of inputs and outputs. Sensors for position synchronization, a sensor for the maximum upper and lower position of the extractor, sensors for scanning the shelf on the extractor and on the dispensing slot are connected to the microprocessor. The outputs control the contactors that connect the actuator motors to the output frequency converter and the display components on the front panel of the universal rack stacker. The reaction time of the control unit is less than $1 \mathrm{~ms}^{-1}$. This reaction time is sufficient to stop the engines in the event of a disaster or emergency stop.

- The first layer was made on an AtXmega128A1 microprocessor because:

- has a sufficient number of communication interfaces, four of which are used,

- has a technology called "event system", where functional quadrature decoding determines the position if the IRC sensor is without the addition of software, 
- operates at a high frequency (32 MHz), so input data is performed immediately and outputs are set in real time.

A position sensor for vertical and horizontal movement is connected to the microprocessor. The positioner regulates the position puller (vertical movement of the shelf). Slave speed, current and torque control of the actuator is provided by a frequency converter.

Layer one communicates with the frequency converter and when this communication is interrupted, it stops the movement of the moving parts of the UCS. The direction of movement is controlled by the digital inputs of the frequency converter, because the response time of the converter to the data communication is so long that it is necessary. When the weight is measured, the frequency converter enters the data into the communication bus and there is a torque data from which the empirically derived shelf weight can be derived. Layer 1 also communicates with the measuring barrier. The height of the shelf is measured each time the shelf moves from the dispensing slot to the UCS on the extractor. The highest point sends to layer two to ensure the best position on the position shelf to the USS tower. Layer one communicates with main layer two and slave layer zero.

The second layer is implemented on an industrial PC, all-in-one version with touch screen. This layer solves the basic algorithms for the movement of the actuators (vertical and horizontal movement), it must ensure the non-collisional movement of the moving parts of the universal shelf-stacker. The second layer must be produced in particular:

- Calculating the position of the shelf in the universal shelf-stacker so that the shelves cannot collide with the mechanical parts of the universal shelf-stacker (reinforcement) or other contents of the shelves or shelves that are located on the shelves.

- Commands for the mechanical movement of the actuators, so that the required shelf is inserted into the dosing slot of the universal shelf-stacker.

- Commands for mechanical movement of the actuators, so that the shelf from the dosing slot is moved to the universal shelf-stacker in the ideal position.

- A sequence of commands to measure the height of the shelf as it moves from the dispensing slot to the universal shelf-stacker on the extractor.

- Sequence of commands for movable drives to determine the weight of the shelf.

- Development of defragmentation of the storage algorithm.

- Operation of a command automaton, which automatically executes commands with a response to the state after the command is executed.

- Equipment recovery after a power failure or emergency stop of the universal shelfstacker or a catastrophe or other unplanned interruption of the work of the universal shelf-stacker.

The second layer uses many data collections that are stored in an external data store. This secure data storage has an internal mechanism to prevent data loss and destruction. The second layer can be connected to the main material management system, which is stored in the universal shelf-stacker and with which it is possible to assign commands to move the shelves to the dispensing slot.

The calculation of the shelf position in the universal shelf-stacker can be performed with other optional parameters. The basic parameter is the economy of storage space use. The storage defragmentation procedure is used to integrate the remaining spaces into the universal shelf-stacker, where the shelves cannot be placed, into several free spaces with sufficient height to store the shelves.

Layer three is also designed on an industrial computer platform for economic reasons as a stand-alone application, which is performed from a layer two application. Some users can 
only log in and log out on the home screen, and after logging in, they can bring any shelf to which they are authorized. This command moves the shelf to the dispensing slot. The same procedure is used to take the shelf into the universal shelf-stacker. The user can also temporarily delete the shelf from use and add the temporarily deleted shelf to the system again and change the percentage of acceleration when moving the shelf. In addition, the administrator can manage users, that is, create and delete users, manage permissions to use shelves by users. The administrator can also insert a new shelf into the system and remove shelves from the system $[4,9]$.

\section{Conclusion}

The menu can be used by employees after logging in and consists of several screens describing the settings of the universal shelf system. On these screens, service personnel can see how the shelves with their basic data are organized, they can clearly define the individual positions of the fields, height, parameters and, in fact, everything that is necessary. Repairmen can oversee the description of mechanical elements, reinforcement. Service personnel check the status of all sensors according to each logical group and check all relevant functions, move independently with actuators, create backups and restore settings of the universal shelf system, initialize modules and restore all necessary parameters in modules from backup.

The hardware platform of the control module layers for the universal shelf system is implemented as described above for minimizing development time, for economic reasons and for programming all described algorithms on all layers. A complex and complicated algorithm for calculating the shelf location to the optimal position and defragmenting the storage space on layer two can be solved on the PLC platform, but this solution is disproportionately more expensive. The second layer can also be implemented on platform 32-bit microprocessors or 8-bit microprocessors (for example AtXmega), but the possibility of debugging on a PC platform significantly reduces the time required for the development of control software.

Acknowledgment: This article was made under support of project: STIMULY MATADOR 1247/2018. Project title: Research and development of modular reconfigurable production systems using Smart Industry principles for automotive with pilot application in MoBearing Line industry.

\section{References}

1. L. Jeroen 1, A. van den Berg, Optimal routing in an automated storage/ retreival system with dedicated storage. IIE Transactions, 31, no. 5, 407-415 (1999)

2. S. Li, D. He, Y Peng, A method for rack area zoning based on task cycle time in automated storage system. International Conference, Transportation Engineering. USA: American Society of Civil Engineers, 961-967 (2007)

3. A. Dombrachev, A. Korshunov, B. Yakimovich. Based on complexity theory the automated normalization system of tool ing. equipment. Avtomatizatsiya i Sovremennye Tekhnologii, Issue 10, 3-8 (2004)

4. T. Dodok, N. Cubonova, M. Císar, et al., Utilization of strategies to generate and optimize machining sequences in CAD/CAM. Conference 12th International Scientific Conference of Young Scientists on Sustainable, Modern and Safe Transport Location: High Tatras, Book Series Procedia Engineering, 192, 113-118 (2017) 
5. V. Tlach, Z. Ságová, I. Kuric, Circular and quasi-circular paths for the industrial robots measuring with the Renishaw Ballbar QC20-W, MATEC Web of Conferences. EDP Sciences. 254 (2017)

6. I. Kuric, M. Cisar, V. Tlach, et al., Technical Diagnostics at the Department of Automation and Production Systems. Book Series Advances in Intelligent Systems and Computing, 835, 474-484 (2019)

7. N. Čuboňová, T. Dodok, Z. Ságová, Optimisation of the machining process using genetic algorithm. Scientific Journal of Silesian University of Technology. Series Transport 104 (2019)

8. A. Elbakian, B. Sentyakov, P. Bozek, I. Kuric, K. Sentyakov, Automated Separation of Basalt Fiber and Other Earth Resources by the Means of Acoustic Vibrations. Acta Montanistica Slovaca, Volume 23, Issue 3, 271-281 (2018)

9. R. Manzini, Warehousing in the Global Supply Chain. Advanced Models. Tools and Applications for Storage systems. London Springer-Verlag London Limited, 483-486, (2012)

10. A. Korshunov, P. Kollár, Technological system for weight measurements in a logistic warehouse. Applied Mechanics and Materials, 11-18 (2015)

11. T. Korbel, W. Bialy, S. Czerwiňski, Ocena stanu technicznego maszyn górniczych w oparciu o kryterium rozkładu Weibulla. Systemy Wspomagania w Inżynierii Produkcji. Górnictwo - perspektywy i zagrożenia. 1(13)/2016. 639-654 (2016)

12. S. Gavlas, P. Durčanský, R. Lenhard and J. Jandacka, EPJ Web of Conferences 92, 02019 (2015)

13. J. Jandacka, M. Holubcik, Š. Papucik, R. Nosek, Combustion of pellets from wheat straw, Acta Montanistica Slovaca, Volume 17, Issue 4, 283-289 (2012)

14. N. Kantova, M. Holubcik, J. Jandacka, A. Čaja, Comparison of particulate matters properties from combustion of wood biomass and brown coal, Procedia Engineering, Volume 192 , pp. 416-420 (2017)

15. M. Hollubcik, J. Jandacka, P. Durcansky, Energy Properties of Wood Pellets Made from the Unusual Woody Plants, AIP Conference Proceedings, Volume 1768 Article Number UNSP 020013 (2016)

16. Y. Turygin, J. Zubkova, D. Maga, Investigation of kinematic error in transfer mechanisms of mechatronic system. 15th International Conference on Mechatronics, Czech Republic; Prague (2012)

17. N. Akatov, I. Klačková, Z. Mingaleva, G. Galieva, N. Shaidurova, Expert technology for risk management in the implementation of QRM in a high-tech industrial enterprise, In časopis: Management Systems in Production Engineering, Volume 27, Issue 4, 250-254 (2019)

18. I. Klačková, I. Zajačko, R. Lenhard, I. Gritsuk, D. Wiecek, Simulation of wood biomass combustion in hot water boiler, In Conference Machine Modelling and Simulations 2019, Liptovský Ján, In IOP Conference Series Materials Science and Engineering, Volume 776, 24th Slovak-Polish International Scientific Conference on Machine Modelling and Simulations - MMS 2019, 3-6 September 2019, Liptovský Ján, Slovakia (2019)

19. I. Kuric, O. Gorobchenko, O. Litikova, I. Gritsuk, V. Mateichyk, K. Bulgakov, I. Klačková, Research of vehicle control informative functioning capacity, In Conference Machine Modelling and Simulations 2019, Liptovský Ján, In IOP Conference Series Materials Science and Engineering, Volume 776, 24th Slovak-Polish International Scientific Conference on Machine Modelling and Simulations - MMS 2019, 3-6 September 2019, Liptovský Ján, Slovakia (2019) 
20. B. Yakimovich, A. Korshunov, V. Sviatskii, Increasing of the Efficiency of Flexible Manufacturing System. In International Conference on Manufacturing Engineering and materials, ICMEM 2016, Nový Smokovec, Slovakia. Procedia Engineering, vol. 149, pp. 581-585, (2016) 